\title{
Maternal undernutrition leads to elevated hepatic triglycerides in male rat offspring due to increased expression of lipoprotein lipase
}

\author{
WEI-FEN ZHU ${ }^{1}$, JIAN-FANG ZHU ${ }^{1}$, LI LIANG ${ }^{1}$, ZHENG SHEN $^{2}$ and YING-MIN WANG ${ }^{1}$ \\ ${ }^{1}$ Department of Pediatrics, The First Affiliated Hospital, College of Medicine, \\ Zhejiang University, Hangzhou, Zhejiang 310058; ${ }^{2}$ Department of Central Laboratory, \\ Children's Hospital of Zhejiang University School of Medicine, Hangzhou, Zhejiang 310003, P.R. China
}

Received February 12, 2015; Accepted December 8, 2016

DOI: $10.3892 / \mathrm{mmr} .2016 .5040$

\begin{abstract}
Small for gestational age (SGA) at birth increases the risk of developing metabolic syndrome, which encompasses various symptoms including hypertriglyceridemia. The aim of the present study was to determine whether maternal undernutrition during pregnancy may lead to alterations in hepatic triglyceride content and the gene expression levels of hepatic lipoprotein lipase (LPL) in SGA male offspring. The present study focused on the male offspring in order to prevent confounding factors, such as estrus cycle and hormone profile. Female Sprague Dawley rats were arbitrarily assigned to receive an ad libitum chow diet or 50\% food restricted diet from pregnancy day 1 until parturition. Reverse transcription quantitative polymerase chain reaction and western blot analysis were used to measure the gene expression levels of hepatic LPL at day 1 and upon completion of the third week of age. Chromatin immunoprecipitation quantified the binding activity of liver X receptor- $\alpha$ (LXR- $\alpha$ ) gene to the LXR response elements (LXRE) on LPL promoter and LPL epigenetic characteristics. At 3 weeks of age, SGA male offspring exhibited significantly elevated levels of hepatic triglycerides, which was concomitant with increased expression levels of LPL. Since LPL is regulated by LXR- $\alpha$, the expression levels of LXR- $\alpha$ were detected in appropriate for gestational age and SGA male offspring. Maternal undernutrition during pregnancy led to an increase in the hepatic expression levels of LXR- $\alpha$, and enriched binding to the putative LXR response elements in the LPL promoter regions in 3-week-old male offspring. In addition, enhanced acetylation of histone H3 [H3 lysine (K)9 and H3K14] was detected surrounding the LPL promoter. The results of the present study indicated that
\end{abstract}

Correspondence to: Professor Li Liang, Department of Pediatrics, The First Affiliated Hospital, College of Medicine, Zhejiang University, 79 Qingchun Road, Hangzhou, Zhejiang 310058, P.R. China

E-mail: zjuhuihui@sina.com.cn

Key words: small for gestational age, hepatic triglycerides, lipoprotein lipase, liver $\mathrm{X}$ receptor $\alpha$, histone modifications maternal undernutrition during pregnancy may lead to an increase in hepatic triglycerides, via alterations in the transcriptional and epigenetic regulation of the LPL gene.

\section{Introduction}

Fetal growth restriction is a common complication of pregnancy, and a significant cause of perinatal morbidity and mortality (1). Numerous studies have reported that adverse conditions during critical periods of development can alter physiological processes leading to metabolic diseases, including type 2 diabetes, hypertension, fatty liver disease and cardiovascular disease $(2,3)$. Furthermore, the majority of small for gestational age (SGA) offspring exhibit compensatory growth during the first 2 years of life, which may contribute to a higher body fat mass from as young as 2-12 months of age (4), and increased body fatness and abdominal fat accumulation during childhood (5) and adulthood (6,7). Considering the social and economic burden of chronic metabolic disease, it is important to elucidate the underlying mechanisms and provide potential strategies for the prevention of long-term metabolic consequences in SGA offspring.

Lipoprotein lipase (LPL), which is a key lipid metabolism enzyme that hydrolyzes triglyceride (TG), provides free fatty acids (FFAs) for cells and affects the maturation of circulating lipoproteins $(8,9)$. LPL has its own developmental genetic program, the activity and expression of which can vary greatly between tissues. In the liver tissue of fetal and neonatal rats high LPL activity has been detected (10); however, the expression of LPL progressively decreases and falls to nearly undetectable levels by the time of weaning (11), as determined by measuring age-related decreases in LPL activity, LPL synthesis and LPL mRNA expression (12). Numerous studies have suggested that, in the pathological state, LPL expression may undergo alterations resulting in various diseases, including atherosclerosis, obesity and diabetes (13-15). The present study aimed to determine whether hepatic LPL gene expression was altered in SGA male rat offspring, and to investigate the potential mechanisms underlying expression alterations.

Several nuclear receptors can activate the transcription of LPL, including peroxisome proliferator-activated receptors, sterol regulatory element-binding protein-1c and liver $\mathrm{X}$ receptors (LXRs) $(13,16,17)$. LXRs are nuclear receptors 
involved in the transcriptional regulation of de novo $\mathrm{TG}$ synthesis. Two isoforms of LXR: Liver X receptor- $\alpha$ (LXR- $\alpha)$ and LXR- $\beta$, have been identified in birds and mammals. As a more selective regulator of LPL than LXR- $\beta$, LXR- $\alpha$ binds to LXR response elements (LXRE), which contain a hexameric nucleotide direct repeat spaced by four bases (DR4), in the LPL promoter in order to govern regulation following activation by oxysterols (17). A previous study demonstrated that maternal protein restriction can alter rat LXR- $\alpha$ expression and lead to long-term epigenetic alterations in LXR target genes associated with lipid homeostasis (18). The present study hypothesized that maternal undernutrition during pregnancy-induced SGA male offspring would exhibit alterations in the expression of LPL, which may be mediated by increased or decreased binding of LXR- $\alpha$ to the LPL gene promoter.

Epigenetics serves a critical function in affecting gene transcription. Previous studies have focused on the identification of epigenetic dysregulation at the promoters of certain genes in SGA offspring. Park et al (19) demonstrated that histone modifications are involved in the effects of uteroplacental insufficiency on islet pancreatic and duodenal homeobox gene 1 transcription in rats. Sohi et al (18) indicated that maternal protein restriction leads to long-term decreases in histone H3 lysine (K)9 (H3K9) and H3K14 surrounding the promoter of the LXR target gene cholesterol $7 \alpha$-hydroxylase, resulting in hypercholesterolemia in SGA offspring. The present study aimed to determine whether post-translational histone modifications may also influence the expression of LPL in SGA male rat offspring.

\section{Materials and methods}

Animal model. Animal experiments were performed at the Laboratory Animal Center of Zhejiang University (Hangzhou, China). All animal experimental procedures were approved by the Animal Ethics Committee of Zhejiang University, School of Medicine.

Briefly, 24 Sprague Dawley rats (16 male and 8 female; SLRC Laboratory Animal Co., Ltd., Shanghai, China) were housed under standard conditions (room temperature, 20-22 ${ }^{\circ} \mathrm{C}$; humidity, 40-60\%). After 1 week of acclimation, male and female rats were mated overnight, and the presence of sperm in a vaginal smear was designated as gestational day 1. Pregnant rats were arbitrarily divided into two groups: The control group continued to receive an ad libitum chow diet; the second group was subjected to food restriction and received $50 \%$ of their usual daily intake until parturition. The pregnant rats delivered spontaneously, and the litter size was randomly culled to eight per mother at birth, in order to assure uniformity of litter size between the SGA and appropriate for gestational age (AGA) litters. All female offspring, as well as male offsprings that did not meeting the criteria for AGA and SGA, were culled. The criteria for AGA were as follows: Offspring of normal intake and birth weight between mean \pm standard deviation (SD). The criteria for SGA were as follows: Offspring of food-restricted mothers and birth weight <-2 SD of the AGA group. Following parturition, mothers from the food restricted group were sacrificed by the administration of $20 \mathrm{ml}$ chloral hydrate (J\&I
Biological, Shanghai, China). The pups were cross-fostered from food-restricted mothers to ad libitum-fed mothers. Both groups were given ad libitum access to food. At 1 day and 3 weeks of age, the rats were sacrificed by anesthesia (chloral hydrate; dose, $2 \mathrm{ml} \mathrm{1-day-old} \mathrm{rats} \mathrm{and} 10 \mathrm{ml}$ for 3-week-old rats). The ad libitum mothers were sacrificed by the administration of $20 \mathrm{ml}$ chloral hydrate. Liver tissue samples were harvested and snap-frozen in liquid nitrogen for subsequent processing.

Hepatic TG content. Total hepatic TG content was determined using a GPO-PAP enzymatic assay (Nanjing Jiancheng Bioengineering Institute, Nanjing, China). Briefly, liver tissue (30-50 mg) was homogenized in ethanol (9 $\mathrm{ml}$ ethanol, $1 \mathrm{~g}$ liver sample), the mixture was microfuged at $664 \mathrm{x}$ g for $10 \mathrm{~min}$ at $4^{\circ} \mathrm{C}$, and the supernatant was transferred to new tubes. The reaction system was prepared according to the manufacturer's instructions. The GPO-PAP enzymatic assay protocol includes the following steps: First, the lipids are broken down via the hydrolysis of triglycerides into glycerol and FFAs. Then the glycerol is converted to glycerol 3-phosphate via adenosine triphosphate and glycerol kinase, and is further converted to dihydroxyacetone phosphate and hydrogen peroxide via glycerophosphate oxidase. Under the effect of peroxidase, red quinones are produced when hydrogen peroxide meets 4-amino-antipyrine and 4-chlorophenol. The color degree of quionoes is propotional to triglyceride concentration. Following a $5 \mathrm{~min}$ incubation at $37^{\circ} \mathrm{C}$, the final mixtures in 96-cell plates were rapidly quantified at $500 \mathrm{~nm}$ using a microplate reader (Varioskan Flash 3001, Thermo Fisher Scientific, Inc., Waltham, MA, USA). Quantification of TG content was based on the following calculation: $\{$ [Sample optical density (OD) value-blank OD value]/(calibration OD value-blank OD value)\} $x$ calibration concentration. Finally, data were expressed as $\mathrm{mg} / \mathrm{g}$ of liver.

RNA isolation and reverse transcription-quantitative polymerase chain reaction $(R T-q P C R)$ analysis. Briefly, total RNA was isolated from the liver tissue samples using TRIzol $^{\circledR}$ reagent (Invitrogen; Thermo Fisher Scientific, Inc.). High-Capacity cDNA Reverse Transcription kit (Applied Biosystems; Thermo Fisher Scientific, Inc.) was used to reverse transcribe $2 \mu \mathrm{g}$ total RNA using the following program: $25^{\circ} \mathrm{C}$ for $10 \mathrm{~min}, 37^{\circ} \mathrm{C}$ for $120 \mathrm{~min}, 85^{\circ} \mathrm{C}$ for $5 \mathrm{~min}$, and a $4^{\circ} \mathrm{C}$ hold. To measure the relative mRNA expression levels, RT-qPCR was performed using an Applied Biosystems StepOnePlus ${ }^{\mathrm{TM}}$ Real-Time PCR system (Applied Biosystems; Thermo Fisher Scientific, Inc.). The PCR cycling conditions were as follows: $94^{\circ} \mathrm{C}$ for $10 \mathrm{~min}$, followed by 40 cycles at $94^{\circ} \mathrm{C}$ for $20 \mathrm{sec}$ and $60^{\circ} \mathrm{C}$ for $1 \mathrm{~min}$. RT-qPCR was performed using SYBR ${ }^{\circledR}$ Select Master Mix (Applied Biosystems; Thermo Fisher Scientific, Inc.) All reactions were performed in triplicate. The relative mRNA expression levels were calculated using the $2^{-\Delta \Delta C q}$ method (20). The primer sequences were as follows: LXR- $\alpha$, forward 5'-GAGAGCATCACCTTCCTCAAG-3', reverse 5'-TCATGGATCTGGAGAACTCAAAG-3'; LPL, forward 5'-ACAGGTGCAATTCCAAGGAG-3', reverse 5'-CTTTCA GCCACTGTGCCATA-3'; and glyceraldehyde 3-phosphate dehydrogenase (GAPDH), forward 5'-GACAACTTTGGC ATCGTGGA-3' and reverse: 5'-ATGCAGGGATGATGT 
TCTGG-3'. Primers were purchased from Thermo Fisher Scientific, Inc.

Western blotting. The liver tissue samples were homogenized in lysis buffer (Beyotime Institute of Biotechnology, Hangzhou, China) and centrifuged at $12,000 \mathrm{x}$ g for $10 \mathrm{~min}$ at $4^{\circ} \mathrm{C}$. The protein concentration was determined using a Bicinchoninic Acid Protein Assay kit (Beyotime Institute of Biotechnology). Equal amounts of protein $(80 \mu \mathrm{g})$ were separated by $10 \%$ sodium dodecyl sulfate (SDS)-polyacrylamide gel electrophoresis and were electroblotted onto a polyvinylidene difluoride membrane $(0.2 \mu \mathrm{m}$ pore size; EMD Millipore, Billerica, MA, USA). The membrane was blocked in 5\% non-fatmilk for $2 \mathrm{~h}$ at room temperature. Following blocking, the membrane was incubated at $4^{\circ} \mathrm{C}$ with anti-LXR- $\alpha$ [dilution 1:3,000; cat. no. ab41902; Abcam (Hong Kong) Ltd., Hong Kong, China), anti-LPL (dilution 1:200; cat. no. sc-32885; Santa Cruz Biotechnology, Inc., Dallas, TX, USA) and anti-GAPDH antibodies (dilution 1:5,000; cat. no. 5174; Cell Signaling Technology, Inc., Danvers, MA USA) for $12 \mathrm{~h}$. The blots were analyzed by ImageJ version 1.39 software (National Institutes of Health, Bethesda, MD, USA). Subsequently, the membrane was incubated with horseradish peroxidase (HRP)-conjugated goat anti-rabbit immunoglobulin $\mathrm{G}(\mathrm{IgG})$ (HRP-labeled (cat. no., A0208; dilution 1:2,000; Beyotime Institute of Biotechnology) and HRP-labeled goat antimouse IgG secondary antibodies (cat. no., A0216; dilution 1:2,000; Beyotime Institute of Biotechnology) for $2 \mathrm{~h}$ at room temperature. Signals were detected using enhanced chemiluminescence, according to the manufacturer's protocol (SuperSignal chemiluminescent substrates; Pierce; Thermo Fisher Scientific, Inc.).

Chromatin immunopreciptation (ChIP). The ChIP assay was performed according to the manufacturer's protocol (EZ-ChIP kit; EMD Millipore). Liver tissue samples (40 mg) were fixed in $1 \%$ formaldehyde for $10 \mathrm{~min}$ at room temperature. Cross-linking was terminated by the addition of glycine (1 M). Following two washes with cold phosphate-buffered saline, the liver tissue was resuspended in $1 \mathrm{ml}$ SDS lysis buffer supplemented with $5 \mu \mathrm{l} 1 \mathrm{X}$ protease inhibitor cocktail II. The lysates were aliquoted to 300-400 $\mu \mathrm{l}$ per microfuge tube and were sonicated on ice, in order to shear the DNA to a length between 200 and 1,000 bp. The sheared crosslinked chromatin was diluted 10 -fold in dilution buffer containing protease inhibitor cocktail II. The chromatin solution was pre-cleared with $60 \mu 1$ protein $\mathrm{G}$ agarose at $4^{\circ} \mathrm{C}$ for $1 \mathrm{~h}$ with rotation. The chromatin solutions were then microfuged at $4,000 \mathrm{x} \mathrm{g}$ for $1 \mathrm{~min}$ at $4^{\circ} \mathrm{C}$ to pellet agarose, and the supernatant was placed in new tubes, with $10 \mu \mathrm{l}$ removed as input. The supernatant fractions were incubated overnight on a rocking platform with antibodies against acetylated histone H3K9 [4 $\mu \mathrm{g}$; cat. no. ab10812; Abcam (Hong Kong) Ltd.], acetylated histone H3K14 [4 $\mu \mathrm{g}$, cat. no. ab52946; Abcam (Hong Kong) Ltd.] and ChIP-grade LXR- $\alpha$ [5 $\mu$ g; cat. no. ab41902; Abcam (Hong Kong) Ltd.] at $4^{\circ} \mathrm{C}$. Subsequently, $60 \mu 1$ protein $\mathrm{G}$ agarose was added to the tubes, which were incubated on a rocking platform for $1 \mathrm{~h}$ at $4^{\circ} \mathrm{C}$. Following centrifugation at $4,000 \times \mathrm{g}$ at $4^{\circ} \mathrm{C}$ for $1 \mathrm{~min}$, the agarose beads containing the immunoprecipitated

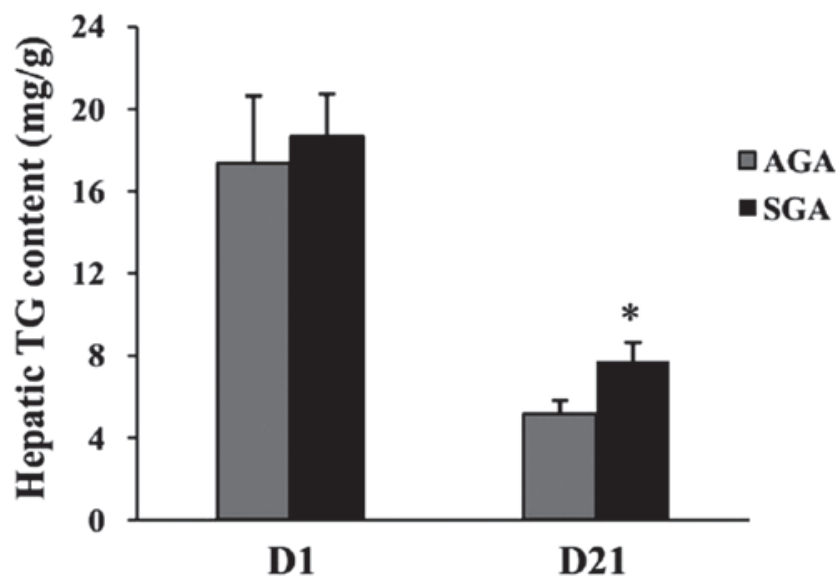

Figure 1. Effects of maternal undernutrition during pregnancy on hepatic triglyceride content in 1-day old and 3-week old rats. Results are expressed as the mean \pm standard error of the mean. ${ }^{*} \mathrm{P}<0.05$, compared with controls of same age.

complexes were washed sequentially in Low Salt Immune Complex Wash Buffer, High Salt Immune Complex Wash Buffer, LiCI Immune Complex Wash Buffer, and 2X TE buffer. The immune complexes were eluted twice with $200 \mu \mathrm{l}$ elution buffer (10 $\mu 120 \%$ SDS, $20 \mu 11 \mathrm{M} \mathrm{NaHCO}_{3}, 170 \mu \mathrm{l}$ sterile distilled water) at room temperature. Elution buffer (200 $\mu \mathrm{l}$ ) was also added to the input tubes. Subsequently, $8 \mu \mathrm{l}$ $5 \mathrm{M} \mathrm{NaCl}$ was added to the elute and the cross-linking of the immunoprecipitated chromatin complexes and input controls were reversed by heating at $65^{\circ} \mathrm{C}$ for $5 \mathrm{~h}$. Following treatment with Proteinase $\mathrm{K}$, Tris- $\mathrm{HCl}$ and EDTA for $2 \mathrm{~h}$ at $45^{\circ} \mathrm{C}$, the DNA was purified, according to the protocol of the manufacturer of the EZ-CHIP kit (EMD Millipore, Billerica, MA, USA).

The putative LXR-binding site in the promoter region of LPL was determined using MatInspector Software (http://www. genomatix.de/online_help/help_matinspector/matinspector_ help.html). Primers were purchased from Invitrogen (Thermo Fisher Scientific, Inc.) and were as follows: Forward (5'-ATT CTCCACCTTGTCCCTTTG-3') and reverse (5'-GCTTGA TTCCCAGAACCCAC-3') primers that amplify -3438 to -3423 promoter regions encompassing the rat LPL LXRE site (GAG GCC_DR4_GAGGGC), and primers (promoter A1, forward 5'-TCTGCTTTGCTGCTGGAACT-3', reverse 5'-AGACGA AACGACGACCTTGA-3'; promoter A2, forward 5'-CACTGT AACGAGGCTCAACG-3', reverse 5'-GTGACATTGCTC CGAGTTGC-3'; and promoter A3, forward 5'-GAGGCAGAA AGTCATGGTCAAATA-3' and reverse 5'-CTCCGTCTTTCA GTACCAGTTTAT-3') surrounding the promoter were used to examine the acetylation status of acetylation of histone $\mathrm{H} 3$ (K9, K14) at the promoter of LPL. For negative controls, ChIP assays were performed using an immunoglobulin $\mathrm{G}$ antibody (1 $\mu \mathrm{g}$; part of the EZ-ChIP kit) to determine the immunospecificity of the antibodies for the LPL promoter. The DNA samples from the input, unbound and bound fractions were determined by qPCR, according to the previously described protocol. The relative abundance of the immunoprecipitated chromatin, as compared with the input chromatin was determined using the $2^{-\Delta \Delta \mathrm{Cq}}$ method (20). 
A

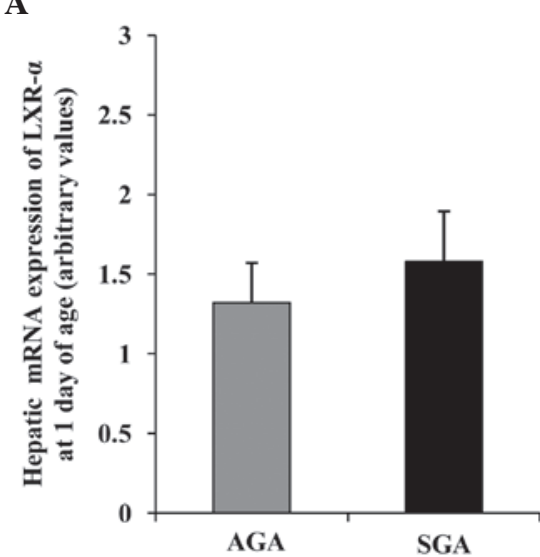

C

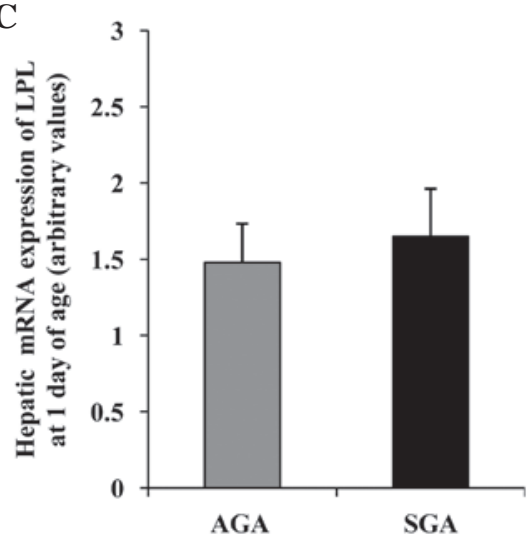

B

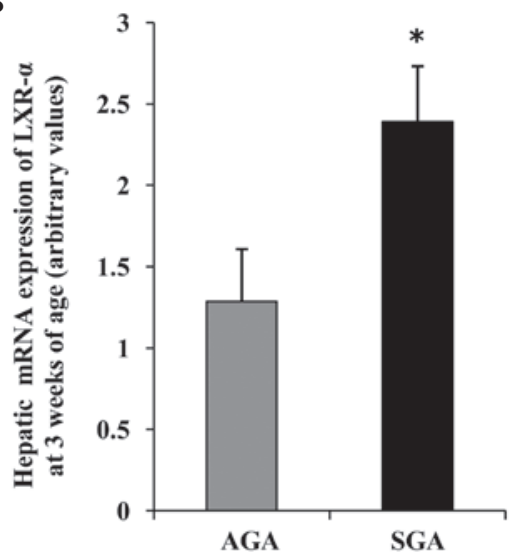

D

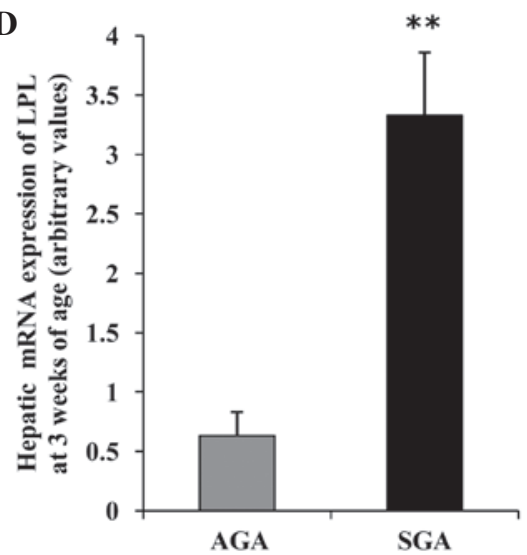

Figure 2. Effects of maternal undernutrition during pregnancy on the hepatic mRNA expression levels of LXR- $\alpha$ and LPL in rat offspring. LXR- $\alpha$ mRNA expression levels in (A) 1-day old and (B) 3-week old rats; LPL mRNA expression levels in (C) 1-day old and (D) 3-week old rats, as determined by reverse transcription-quantitative polymerase chain reaction. Data are presented as arbitrary values, and are presented as the mean \pm standard error of the mean. ${ }^{*} \mathrm{P}<0.05$ and ${ }^{* *} \mathrm{P}<0.01$ vs. the AGA rats. SGA, small for gestational age; AGA, appropriate for gestational age; LXR, liver X receptor; LPL, lipoprotein lipase.

Statistical analysis. SPSS 18.0 (SPSS, Inc., Chicago, IL, USA) was used for data analysis. All data are expressed as the mean \pm standard error of the mean. Statistical significance was calculated using Student's t-test. $\mathrm{P}<0.05$ was considered to indicate a statistically significant difference.

\section{Results}

Hepatic TG content. At 1 day of age, no differences were evident in hepatic TG levels between the AGA and SGA male rats (AGA, $17.39 \pm 3.25 \mathrm{mg} / \mathrm{g}$; SGA, $18.68 \pm 2.05 \mathrm{mg} / \mathrm{g}$; $\mathrm{P}>0.05$ ) (Fig. 1). At 3 weeks of age, the hepatic TG levels were increased in the SGA male rats (AGA, $5.18 \pm 0.63 \mathrm{mg} / \mathrm{g}$; SGA, $7.73 \pm 0.91 \mathrm{mg} / \mathrm{g} ; \mathrm{P}<0.05$ ), as compared with the AGA rats.

Hepatic LXR-a mRNA expression levels are increased, concomitant with an increase in LPL mRNA in 3-week-old $S G A$ rats. The hepatic mRNA expression patterns in both groups are presented in Fig. 2. At 1 day of age, there was no difference in the mRNA expression levels of LXR- $\alpha$ and LPL between the AGA and SGA male rats (Fig. 2A and C). However, at 3 weeks of age, the SGA male rats had significantly increased mRNA expression levels of LXR- $\alpha$ and LPL, as compared with the AGA rats $(\mathrm{P}<0.05$ and $\mathrm{P}<0.01$, respectively) (Fig. 2B and D).

Hepatic LXR- $\alpha$ protein expression levels are increased, concomitant with an increase in LPL protein in 3-week-old $S G A$ rats. To obtain further information regarding the differences in protein expression, western blotting was performed (Fig. 3). The protein expression levels of LXR- $\alpha$ and LPL were increased $(\mathrm{P}<0.05)$ in the SGA male rats, as compared with the AGA rats at 3 weeks of age (Fig. 3B and D); however, no differences were detected between the SGA and AGA male rats at 1 day of age (Fig. 3A and C).

$L X R$ - $\alpha$ binding to the LXRE in the promoter regions of $L P L$ is increased in 3-week-old SGA rats. To determine whether there were alterations in the recruitment of LXR- $\alpha$ to the promoter regions of LPL containing a well-characterized LXRE site, ChIP analyses were performed with antibodies specific for LXR- $\alpha$. Negative controls demonstrated that the immunoprecipitations were specific for the indicated antibodies. At 3 weeks of age, the SGA male rats exhibited a marked increase in the binding of LXR- $\alpha$ to the promoter regions of LPL, as compared with in the AGA rats $(\mathrm{P}<0.05)$ (Fig. 4). 
A
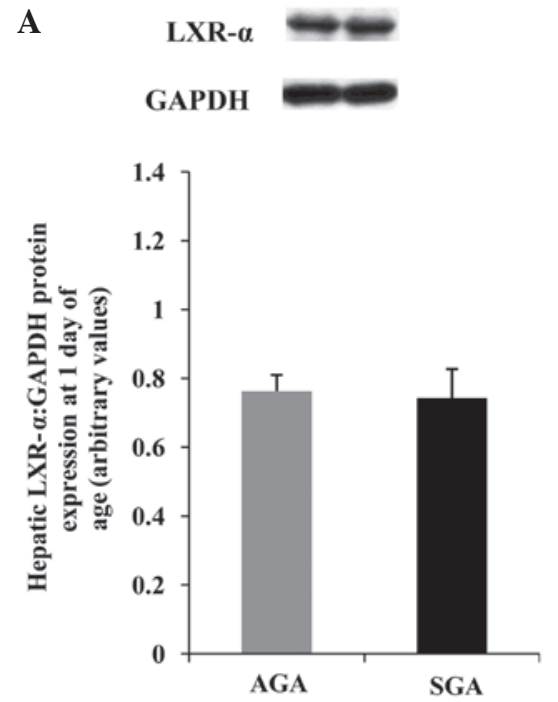

c
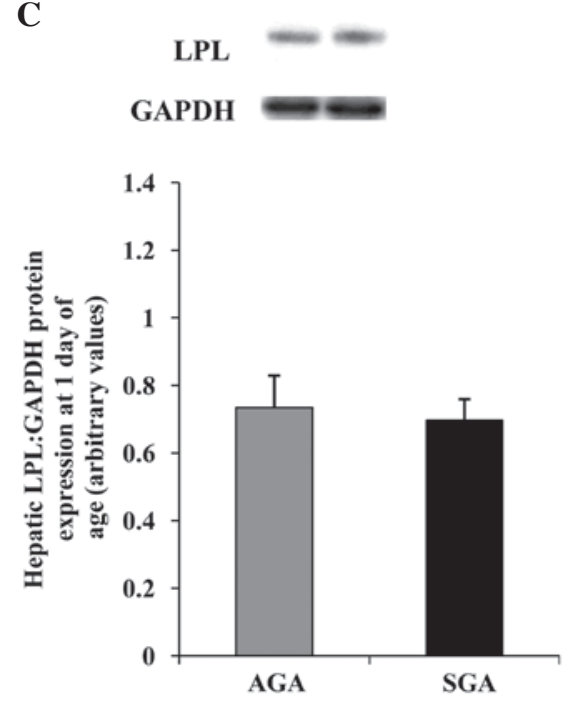

B
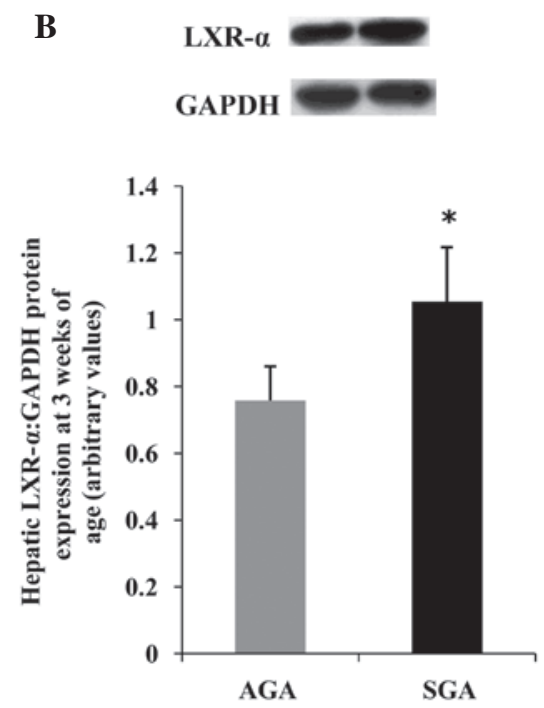

D
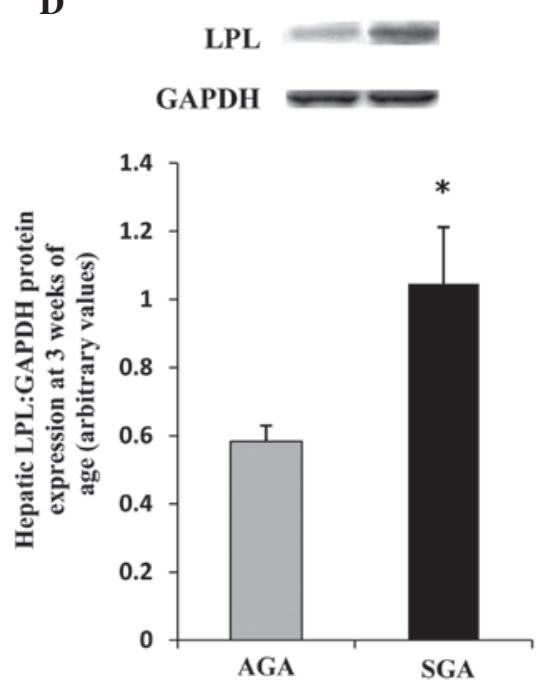

Figure 3. Effects of maternal undernutrition during pregnancy on the hepatic protein expression levels of LXR- $\alpha$ and LPL in rat offspring. LXR- $\alpha$ protein expression levels in (A) 1-day old and (B) 3-week old rats; LPL protein expression levels in (C) 1-day old and (D) 3-week old rats, as determined by western blotting. Protein expression levels were normalized relative to the expression of GAPDH. Data are presented as arbitrary values, and are presented as the mean \pm standard error of the mean. ${ }^{*} \mathrm{P}<0.05$ vs. the AGA rats. SGA, small for gestational age; AGA, appropriate for gestational age; LXR, liver X receptor; LPL, lipoprotein lipase; GAPDH, glyceraldehyde 3-phosphate dehydrogenase.

Acetylation oflysine residues 9 and 14 on histone $\mathrm{H} 3$ surrounding the promoter regions of LPL is increased in 3-week-old SGA rats. ChIP was further used to investigate whether chromatin remodeling could be a factor influencing the observed increase in LPL mRNA and protein expression levels in 3-week-old male SGA rats. Three sites (A1: -87 to +177 ; A2: -136 to -533 and A3: -644 to -896 ) along the LPL promoter were analyzed. The hepatic levels of acetylated histone $\mathrm{H} 3 \mathrm{~K} 9$ in the LPL promoter A1, A2 and A3 regions of SGA rats were increased 1.71-fold, 2.73-fold and 2.50-fold, respectively $(\mathrm{P}<0.05)$, as compared with the AGA rats (Fig. 5A). The hepatic levels of acetylated histone $\mathrm{H} 3 \mathrm{~K} 14$ in the LPL promoter A1, A2 and A3 regions of SGA rats were increased 1.69-fold, 1.86-fold and 2.67-fold, respectively $(\mathrm{P}<0.05)$, as compared with the AGA rats (Fig 5B).

\section{Discussion}

The present study demonstrated that 3-week-old SGA male offspring exhibited increased hepatic TG levels. In liver tissue, the fatty acid biosynthesis pathway facilitates excess energy storage, either as cytosolic lipid droplets or circulating TG-rich lipoproteins (21). These TG may provide energy during times of deficiency following oxidation; however, the excess accumulation of hepatic TG is a risk factor for cardiovascular disease. Therefore, a better understanding regarding the molecular determinants that control fatty acid metabolism and hepatic TG levels may facilitate the development of effective interventions that reduce the metabolic risk factors for SGA male offspring.

The results of the present study demonstrated that alterations in hepatic TG content were closely paralleled with changes in hepatic mRNA and protein expression levels of LPL, which implicated LPL in the development of hepatic lipid dysregulation. A previous study reported that in fetal plasma from pregnancies characterized by SGA, altered LPL expression appeared to be associated with changes in FFA placental exchange, which may contribute to an abnormal lipid profile (22). Kim et al (23) demonstrated that mice with 


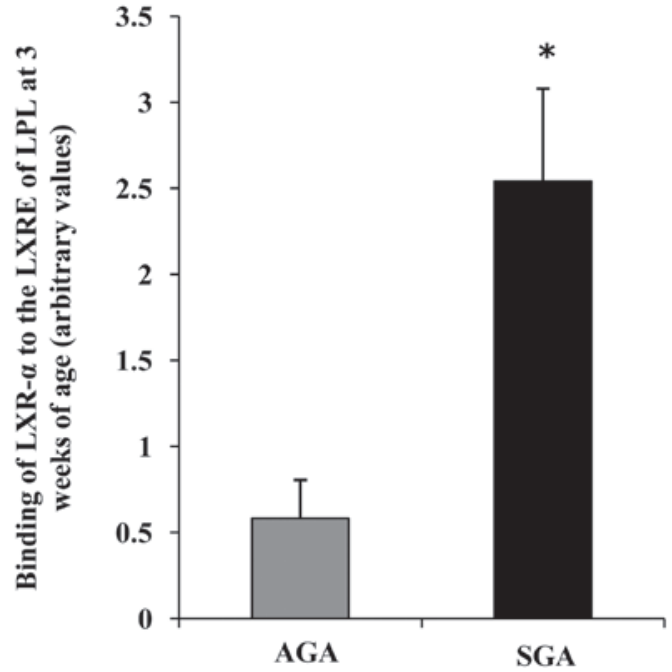

Figure 4. Effects of maternal undernutrition on the binding of LXR- $\alpha$ to the promoter region of LPL in rat livers at 3 weeks of age. Putative LXRE sites were determined using MatInspector software (Genomatix). Quantitative polymerase chain reaction analysis was performed with primers specific to the proposed LXRE sites. Data are represented as arbitrary values, and are presented as the mean \pm standard error of the mean. ${ }^{*} \mathrm{P}<0.05$ vs. the AGA rats. SGA, small for gestational age; AGA, appropriate for gestational age; LXR, liver X receptor; LPL, lipoprotein lipase; LXRE, LXR response elements.

liver-specific LPL overexpression manifested hepatic steatosis and insulin resistance. In addition, at the time of weaning, LPL mRNA expression is nearly undetectable in normal rat livers; therefore, the hepatic expression of LPL in SGA male rats may not only enable the liver to hydrolyze TG from chylomicrons and very-low-density lipoprotein, but may also lead to an increase in the hepatic uptake of FFA, which may induce hepatic steatosis (24).

To the best of our knowledge, LPL mRNA expression levels have been widely evaluated in the SGA placenta. Gauster et al (25) compared the LPL expression between normal pregnancies and those complicated with SGA; the results demonstrated that LPL was markedly increased (2.4-fold; $\mathrm{P}<0.015)$ in SGA placentas. In addition, Tabano et al (26) detected an increase in LPL mRNA expression in severe SGA cases with abnormal umbilical blood flow, as compared with AGA placentas. The results of the present study combined with findings from previous studies led us to hypothesize that increased expression levels of LPL may persist into postnatal life, and may be involved in the development of metabolic disease in SGA male offspring.

It is well known that the regulation of LPL gene expression is complex, occurring at transcriptional, translational and post-translational levels. The present study hypothesized that alterations in LPL expression in SGA rats may occur via sensitive upstream transcriptional regulators, such as the LXR- $\alpha$ gene. To further characterize the mechanism involved, ChIP coupled with qPCR methods were used to study the exact mechanism. The results suggested that LPL expression is mediated by LXR- $\alpha$, which interacts with LXRE sequences spanning the -3438 to -3423 promoter regions in hepatic LPL. The nuclear receptor LXR- $\alpha$ is emerging as a key regulator of lipid homeostasis, which is primarily expressed in the liver, intestine, adipose tissue and macrophages. In addition
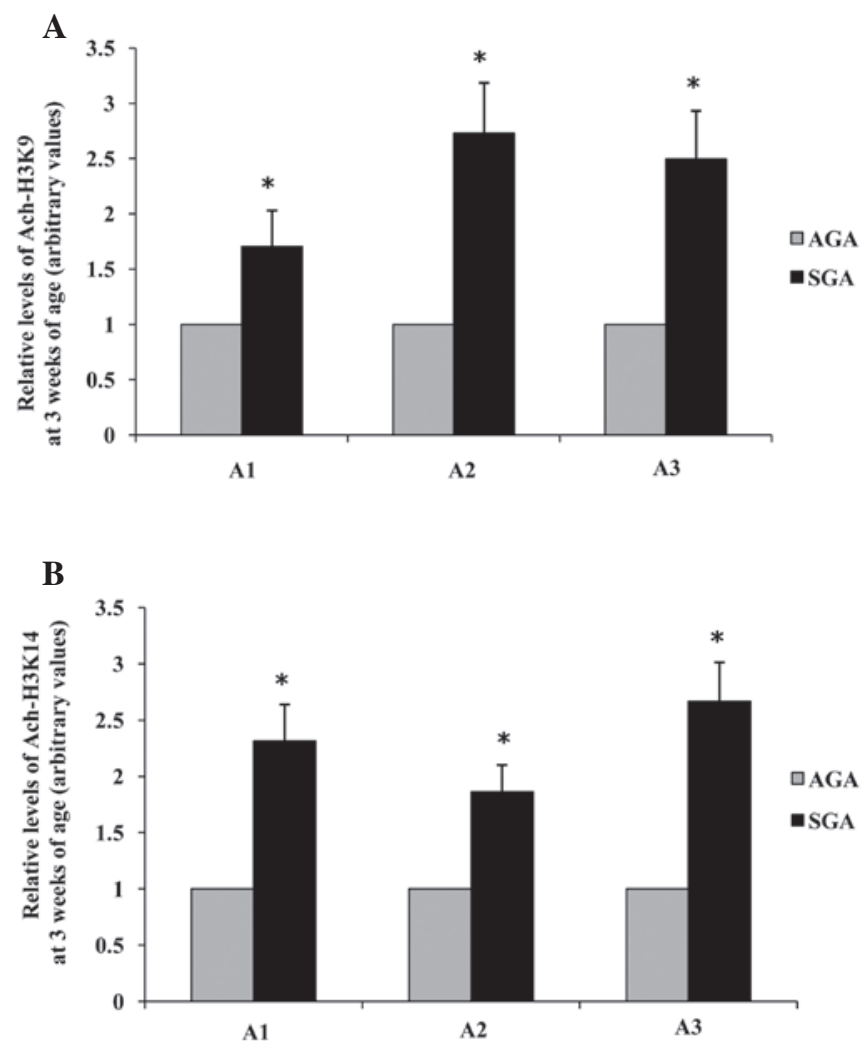

Figure 5. Effects of maternal undernutrition on the epigenetic regulation of LPL promoter regions in rat livers at 3 weeks of age. (A) Acetylation of H3K9 and (B) H3K14. Quantitative polymerase chain reaction analysis was performed using primers specific to the proposed LPL element sites (A1, -87 to +177 ; A2, -136 to -533 ; A3, -644 to -896 ). Data are presented as arbitrary values, and are presented as the mean \pm standard error of the mean. " $\mathrm{P}<0.05$, vs. the AGA rats. SGA, small for gestational age; AGA, appropriate for gestational age; LPL, lipoprotein lipase; Ach, acetylated; H3K, histone H3 lysine.

to LPL, LXR- $\alpha$ also regulates numerous genes involved in fatty acid synthesis, including fatty acid synthase, acetyl CoA carboxylase and the sterol-regulatory element binding protein 1 (27-29). Previous animal studies have demonstrated that administration of the LXR ligand, TO-901317, may cause severe fatty liver and obesity $(30,31)$. Since overexpression of the LXR- $\alpha$ gene may increase fatty acid synthase via its target genes, it may be considered a suitable target for therapeutic intervention, in order to prevent hepatic fatty infiltration in SGA male offspring.

The present study demonstrated that gene expression is not the only molecular phenotype affected by maternal nutritional manipulation. Epigenetic states can also be modified by environmental factors, resulting in transcriptional expression or silencing. Acetylation of H3K9 and H3K14 is generally believed to be associated with actively transcribed genes $(32,33)$, which are congruent with the increased mRNA and protein expression levels of LPL observed in the present study. Since hepatic development occurs throughout neonatal and early postnatal life, it is plausible that targeting this short period of development may help reverse or prevent adverse hepatic epigenetic phenotypes in SGA offspring.

In conclusion, the present study demonstrated that maternal undernutrition during pregnancy and subsequent SGA may result in postnatal alterations in the epigenetic characteristics 
of the LPL gene, and increased binding of LXR- $\alpha$ to the LXRE in LPL promoter regions. These alterations were associated with predictable changes in LPL mRNA and protein expression levels, and may result in elevated hepatic TG content.

\section{Acknowledgements}

The present study was supported by the National Science Foundation of China (grant nos. 81170733 and 81000267).

\section{References}

1. Lees C, Marlow N, Arabin B, Bilardo CM, Brezinka C, Derks JB, Duvekot J, Frusca T, Diemert A, Ferrazzi E, et al; TRUFFLE Group: Perinatal morbidity and mortality in early-onset fetal growth restriction: Cohort outcomes of the trial of randomized umbilical and fetal flow in Europe (TRUFFLE). Ultrasound Obstet Gynecol 42: 400-408, 2013.

2. Gluckman PD, Hanson MA, Cooper C and Thornburg KL: Effect of in utero and early-life conditions on adult health and disease. N Engl J Med 359: 61-73, 2008.

3. Ross MG and Beall MH: Adult sequelae of intrauterine growth restriction. Semin Perinatol 32: 213-218, 2008.

4. Hediger ML, Overpeck MD, Kuczmarski RJ, McGlynn A, Maurer KR and Davis WW: Muscularity and fatness of infants and young children born small- or large-for-gestational-age. Pediatrics 102: E60, 1998.

5. Ong KK, Ahmed ML, Emmett PM, Preece MA and Dunger DB: Association between postnatal catch-up growth and obesity in childhood: Prospective cohort study. BMJ 320: 967-971, 2000.

6. Law CM, Barker DJ, Osmond C, Fall CH and Simmonds SJ Early growth and abdominal fatness in adult life. J Epidemiol Community Health 46: 184-186, 1992.

7. Parsons TJ, Power C and Manor O: Fetal and early life growth and body mass index from birth to early adulthood in 1958 British cohort: Longitudinal study. BMJ 323: 1331-1335, 2001

8. Ramasamy I: Recent advances in physiological lipoprotein metabolism. Clin Chem Lab Med 52: 1695-1727, 2014.

9. Goldberg IJ and Merkel M: Lipoprotein lipase: Physiology, biochemistry, andmolecular biology. Front Biosci 6: D388-D405, 2001.

10. Llobera M, Montes A and Herrera E: Lipoprotein lipase activity in liver of the rat fetus. Biochem Biophys Res Commun 91: 272-277, 1979.

11. Staels B and Auwerx J: Perturbation of developmental gene expression in rat liver by fibric acid derivatives: Lipoprotein lipase and alpha-fetoprotein as models. Development 115 $1035-1043,1992$.

12. Panadero M, Bocos C and Herrera E: Relationship between lipoprotein lipase and peroxisome proliferator-activated receptor-alpha expression in rat liver during development.Physiol Biochem 62: 189-198, 2006.

13. Schoonjans K, Peinado-Onsurbe J, Lefebvre AM, Heyman RA, Briggs M, Deeb S, Staels B and Auwerx J: PPARalpha and PPARgamma activators direct a distinct tissue-specific transcriptional response via a PPRE in the lipoprotein lipase gene. EMBO15: 5336-5348, 1996.

14. Dobrian AD, Lazar V, Sinescu C, Mincu D and Simionescu M: Diabetic state induces lipid loading and altered expression and secretion of lipoprotein lipase in human monocyte-derived macrophages. Atherosclerosis 153: 191-201, 2000.

15. Wang H, Astarita G, Taussiq MD, Bharadwaj KG, DiPatrizio NV, Nave KA, Piomelli D, Goldberg IJ and Eckel RH: Deficiency of lipoprotein lipase in neurons modifies the regulation of energy balance and leads to obesity. Cell Metab 13: 105-113, 2011.

16. Schoonjans K, Gelman L, Haby C, Briggs M and Auwerx J: Induction of LPL gene expression by sterols is mediated by a sterol regulatory element and is independent of the presence of multiple E boxes. J Mol Biol 304: 323-334, 2000.
17. Zhang Y, Repa JJ, Gauthier K and Mangelsdorf DJ: Regulation of lipoprotein lipase by the oxysterol receptors, LXRalpha and LXRbeta. J Biol Chem 276: 43018-43024, 2001.

18. Sohi G, Marchand K, Revesz A, Arany E and Hardy DB: Maternal protein restriction elevates cholesterol in adult rat offspring due to repressive changes in histone modification at the cholesterol 7alpha-hydroxlase promoter. Mol Endocrinol 25: 785-798, 2011.

19. Park JH, Stoffers DA, Nicholls RD and Simmons RA: Development of type 2 diabetes following intrauterine growth retardation in rats is associated with progressive epigenetic silencing of Pdx1. J Clin Invest 118: 2316-2324, 2008.

20. Livak KJ and Schmittgen TD: Analysis of relative gene expression data using real-time quantitative PCR and the 2(-Delta Delta C(T)) Method. Methods 25: 402-408, 2001.

21. Jensen-Urstad AP and Semenkovich CF: Fatty acid synthase and liver triglyceride metabolism: Housekeeper or messenger? Biochim Biophys Acta 1821: 747-753, 2012.

22. Cetin I, Giovannini N, Alvino G, Agostoni C, Riva E, Giovannini $M$ and Pardi $G$ : Intrauterine growth restriction is associated with changes in polyunsaturated fatty acid fetal-maternal relationships. Pediatr Res 52: 750-755, 2002.

23. Kim JK, Fillmore JJ, Chen Y, Yu C, Moore IK, Pypaert M, Lutz EP, Kako Y, Velez-Carrasco W, Goldberg IJ, et al: Tissue-specific overexpression of lipoprotein lipase causes tissue-specific insulin resistance. Proc Natl Acad Sci USA 98: 7522-75227, 2001.

24. Pardina E, Baena-Fustegueras JA, Llamas R, Catalán R, Galard R, Lecube A, Fort JM, Llobera M, Allende H, Vargas V and Peinado-Onsurbe J: Lipoprotein lipase expression in livers of morbidly obese patients could be responsible for liver steatosis. Obes Surg 19: 608-616, 2009.

25. Gauster M, Hiden U, Blaschitz A, Frank S, Lang U, Alvino G, Cetin I, Desoye G and Wadsack C: Dysregulation of placental endothelial lipase and lipoprotein lipase in intrauterine growth-restricted pregnancies. J Clin Endocrinol Metab 92: 2256-2263, 2007.

26. Tabano S, Alvino G, Antonazzo P, Grati FR, Miozzo M and Cetin I: Placental LPL gene expression is increased in severe intrauterine growth-restricted pregnancies. Pediatr Res 59: 250-253, 2006 .

27. Yu H, Wu J, Yang M, Guo J, Zheng L, Peng M, Zhang Q, Xiang Y, Cao J and Shen W: Involvement of liver X receptor alpha in histone modifications across the target fatty acid synthase gene. Lipids 47: 249-257, 2012.

28. Talukdar S and Hillgartner FB: The mechanism mediating the activation of acetyl-coenzyme A carboxylase-alpha gene transcription by the liver X receptor agonist T0-901317.Lipid Res 47: 2451-2461, 2006

29. Repa JJ, Liang G, Ou J, Bashmakov Y, Lobaccaro JM, Shimomura I, Shan B, Brown MS, Goldstein JL and Mangelsdorf DJ: Regulation of mouse sterol regulatory element-binding protein-1c (SREBP-1c) by oxysterol receptors, LXRalpha and LXRbeta. Genes Dev 14: 2819-2830, 2000.

30. Cao G, Liang Y, Broderick CL, Oldham BA, Beyer TP, Schmidt RJ, Zhang Y, Stayrook KR, Suen C, Otto KA, et al: Antidiabetic action of a liver $\mathrm{x}$ receptor agonist mediated by inhibition of hepatic gluconeogenesis. J Biol Chem 278: 1131-1136, 2003

31. Chisholm JW, Hong J, Mills SA and Lawn RM: The LXR ligand T0901317 induces severe lipogenesis in the $\mathrm{db} / \mathrm{db}$ diabetic mouse. J Lipid Res 44: 2039-2048, 2003.

32. Kim JM, Liu H, Tazaki M, Nagata M and Aoki F: Changes in histone acetylation during mouse oocyte meiosis. J Cell Biol 62: 37-46, 2003.

33. Schiltz RL, Mizzen CA, Vassilev A, Cook RG, Allis CD and Nakatani Y: Overlapping but distinct patterns of histone acetylation by the human coactivators $\mathrm{p} 300$ and PCAF within nucleosomal substrates. J Biol Chem 274: 1189-1192, 1999. 